\title{
Is there a link between glucose levels and heart failure? An update
}

\author{
Existiria uma ligação entre os níveis de glicose e \\ insuficiência cardíaca? Uma atualização
}

Arnaldo Schainberg ${ }^{1}$, Antônio Ribeiro-Oliveira $\mathrm{Jr}^{2}{ }^{2}$, José Marcio Ribeiro ${ }^{3}$

\begin{abstract}
'Hospital Governador Israel Pinheiro, Instituto de Previdência dos Servidores do Estado de Minas Gerais (IPSEMG), Departamento de Endocrinologia Belo Horizonte, MG, Brazil ${ }^{2}$ Universidade Federal de Minas Gerais (UFMG), Faculdade de Medicina, Laboratório de Pesquisa em Endocrinologia, Belo Horizonte, MG, Brazil ${ }^{3}$ Hospital Governador Israel Pinheiro, IPSEMG, Departamento de Cardiologia Belo Horizonte, MG, Brazil
\end{abstract}

\section{SUMMARY}

It has been well documented that there is an increased prevalence of standard cardiovascular (CV) risk factors in association with diabetes and with diabetes-related abnormalities. Hyperglycemia, in particular, also plays an important role. Heart failure (HF) has become a frequent manifestation of cardiovascular disease (CVD) among individuals with diabetes mellitus. Epidemiological studies suggest that the effect of hyperglycemia on $\mathrm{HF}$ risk is independent of other known risk factors. Analysis of datasets from populations including individuals with dysglycemia suggests the pathogenic role of hyperglycemia on left ventricular function and on the natural history of HF. Despite substantial epidemiological evidence of the relationship between diabetes and $\mathrm{HF}$, data from available interventional trials assessing the effect of a glucose-lowering strategy on CV outcomes are limited. To provide some insight into these issues, we describe in this review the recent important data to understand the natural course of $\mathrm{CV}$ disease in diabetic individuals and the role of hyperglycemia at different times in the progression of HF. Arq Bras Endocrinol Metab. 2010;54(5):488-97

\section{Keywords}

Prediabetic state; blood glucose; hyperglycemia; ventricular dysfunction, left; heart failure

\section{SUMÁRIO}

Já foi bem documentado um aumento da prevalência dos fatores de risco cardiovascular convencional em portadores de diabetes melito e em pessoas com as anormalidades relacionadas ao diabetes. A hiperglicemia, particularmente, teria um papel crítico. A insuficiência cardíaca (IC) tem se tornado uma manifestação frequente da doença cardiovascular em indivíduos com diabetes. Estudos epidemiológicos sugerem que o efeito da hiperglicemia no risco para IC é independente dos outros fatores de risco. A análise dos dados de populações que incluem indivíduos com disglicemia sugere um papel patogênico da hiperglicemia na função do ventrículo esquerdo na história natural da IC. A despeito de evidências epidemiológicas na relação entre diabetes e IC, os dados disponíveis de estudos clínicos de intervenção para avaliar o efeito da estratégia de redução da glicose sobre os desfechos cardiovasculares ainda são limitados. Para trazer alguma compreensão nesse tópico, descrevemos nesta revisão os dados recentes e importantes para entender a história natural da doença cardiovascular em indivíduos com diabetes e o papel da hiperglicemia em diferentes períodos na progressão da doença. Arq Bras Endocrinol Metab. 2010;54(5):488-97

\section{Descritores}

Estado pré-diabético; glicemia; hiperglicemia; disfunção ventricular esquerda; insuficiência cardíaca

\section{INTRODUCTION}

$\mathrm{T}$ his review was performed by conducting an electronic literature search in medical databases (MEDLINE, SciELO, LILACS from 1980 to 2009), and a manual search in textbooks and review articles. We used the following key words: blood glucose; hyperglycemia; prediabetic state; cardiomyopathies; ventricular dysfunction, left; heart failure; echocardiography, and Doppler. The aim of this review was to search and provide a better understanding to the current knowledge of the 
relationship between glucose levels and cardiovascular disease, highlighting the importance of early subtle changes either in glucose levels or cardiac structure and the relationship between them.

\section{DIABETES MELLITUS AND HEART FAILURE}

Heart failure (HF) is considered a progressive disorder that can be represented as a clinical continuum. The American College of Cardiology/American Heart Association (ACC/AHA) updated 2005 guidelines for the management of chronic $\mathrm{HF}$, clearly recognizing 4 stages in this continuum (1), and linking these stages to the natural history of HF and providing therapeutic recommendations. Patients defined as Stage A are those with risk factors that clearly predispose toward the development of HF such as patients with coronary artery disease, hypertension, or diabetes who do not yet demonstrate impaired left ventricular function, hypertrophy, or geometric chamber distortion; whereas patients who are asymptomatic but demonstrate left ventricular hypertrophy $(\mathrm{LVH})$ and/or impaired left ventricular function would be designated as Stage B. Structural heart disease with prior or current symptoms of HF characterizes Stage C, and refractory $\mathrm{HF}$ requiring specialized interventions such as heart transplant or chronic inotrope treatment characterizes Stage D. Left ventricu$\operatorname{lar}(\mathrm{LV})$ diastolic function is affected earlier than systolic function in the development of HF and cardiovascular disease (CVD) in patients with diabetes mellitus (DM) (2). The diastolic filling abnormalities in type 2 diabetes mellitus (T2DM) subjects without clinical evidence of heart disease appear to be common and suggest the presence of early subclinical alterations in cardiac function.

Hyperglycemia is the diagnostic feature of DM, the target for antidiabetic therapy and, together with $\mathrm{HbAlC}$, the marker of glucose control. The plasma glucose level for the diagnosis of DM is currently based on the risk of microvascular complications. Maintaining a good glucose control has been associated with marked reduction in the risk of developing retinopathy, nephropathy, and neuropathy in both type 1 and type 2 diabetic patients $(3,4)$. Moreover, intensive diabetes therapy has been shown to have long-term beneficial effects on the risk of CVD in both type 1 and type 2 diabetes (5). A new meta-analysis suggests that intensive control of blood glucose levels significantly reduces the risk of myocardial infarction (MI) and coronary heart disease $(\mathrm{CHD})$ events and has no effect on all-cause mortality. These findings, which include five of the pivotal diabetes studies including The United Kingdom Prospective Diabetes Study (UKPDS), Action in Diabetes and Vascular Disease: Preterax and Diamicron Modified Release Controlled Evaluation (ADVANCE), Veterans Affairs Diabetes Trial (VADT), Action to Control Cardiovascular Risk in Diabetes (ACCORD), and the Prospective Pioglitazone Clinical Trial in Macrovascular Events (PROACTIVE), have caused a stir regarding blood glucose control, and they give support to continued therapy targeting hemoglobin $\mathrm{A}_{\mathrm{lc}}$ $\left(\mathrm{HbA}_{\mathrm{lc}}\right)$ to less than 7.0\% (6).

Type $2 \mathrm{DM}$ is associated with an increased risk of HF. The mechanisms underlying this association remain controversial, and there may be at least three possibilities. First, T2DM is often associated with hypertension and obesity, and these important risk factors may in part account for the association of T2DM with HF. Second, T2DM may lead to HF by impairing both large and small artery function, and it has consequently been related to atherothrombotic $\mathrm{CHD}$, diabetic microangiopathy, small artery endothelial dysfunction and increased arterial stiffness. Third, T2DM may cause a distinct metabolic cardiomyopathy related to hyperglycemia and/or hyperinsulinemia (7).

Whether hyperglycemia is the culprit of such an elevated cardiovascular (CV) risk remains to be elucidated, in case it could be a simple useful marker for a condition characterized by concomitance of multiple cardiovascular risk factors. The period of exposure to hyperglycemia before the diagnosis of T2DM is likely to contribute to the hyperglycemic memory, and this may account for later complications in individuals who achieve and maintain near-normal glucose control from the time of diagnosis on.

Diabetes is a strong risk factor for $\mathrm{CV}$ events such as MI and stroke. A growing body of evidence is now showing that CV risk is not restricted to glucose levels above the thresholds that differentiate DM from nondiabetic states. Indeed, CV risk is predicted by the degree of glucose elevation and not by the presence or absence of DM per se (8). Even in early reports, diabetic cardiomyopathy was related to hyperglycemia-induced myocardial microvascular damage because of its association with glomerulosclerosis and retinopathy (9).

HF has become a frequent manifestation of CVD among individuals with DM (10). The diabetic cardiomyopathy was initially classified as a dilated cardiomyopathy as it featured prominent LV enlargement and 
depressed LV systolic function. Over the last decade, however, diastolic LV dysfunction was identified as an earlier manifestation of diabetic cardiomyopathy (2), and this restrictive phenotype of diabetic cardiomyopathy was also related to hyperglycemia. Impaired diastolic LV distensibility was thought to result from advanced glycation end-products (AGE) causing strong collagen cross-links in the myocardial extracellular matrix (11).
However, myocardial damage does not only result from hyperglycemia but also from hyperinsulinemia, inflammation, and oxidative stress (12).

Thus, the relationship between glucose and CV events is clearly not limited to diabetic patients, and the degree of hyperglycemia, as measured by either plasma glucose or HbAlc levels, seems to be progressively related to the risk for a new or recurrent CV event (Table 1).

Table 1. Summary of the most important studies of dysglycemia and heart failure

\begin{tabular}{|c|c|c|c|c|}
\hline Study & Design & Subjects & Results & Ref. \\
\hline UKPDS 35 & Prospective observational study & $\begin{array}{l}\mathrm{n}=4,585 \text { patients (white, Asian } \\
\text { Indian, and Afro-Caribbean) }\end{array}$ & $\begin{array}{l}\text { Incidence of clinical complications was significantly } \\
\text { associated with glycemia } \\
\text { No threshold of risk for any end point } \\
16 \% \text { increase in the risk for HF for each } 1 \% \text { rise in A1C }\end{array}$ & 13 \\
\hline EPIC Norfolk & $\begin{array}{l}\text { Epidemiologic study } \\
\text { 6-year follow-up }\end{array}$ & $\begin{array}{c}n=10,000 \text { subjects } \\
\text { (45 to } 79 \text { years) }\end{array}$ & $\begin{array}{l}21 \% \text { increase in CV events for each } 1 \% \text { rise in } \mathrm{A} 1 \mathrm{C}>5 \% \\
\text { Increase in mortality of } 24 \% \text { in men and } 28 \% \text { in women } \\
\text { Increase in the risk of a CHD event by } 40 \% \text { and } 26 \% \text { in } \\
\text { mortality for each } 1 \% \text { of } A 1 C>7 \%\end{array}$ & 14 \\
\hline $\begin{array}{l}\text { Framingham } \\
\text { Offspring Study }\end{array}$ & $\begin{array}{l}\text { Community-based observational } \\
\text { study of risk factors for CVD }\end{array}$ & $n=3,370$ & $\begin{array}{l}\text { Independent relationship between markers of dysglycemia, } \\
\text { including A1c, and incident CV events }\end{array}$ & 15 \\
\hline $\begin{array}{l}\text { OPTIMAAL Study } \\
\text { Group }\end{array}$ & $\begin{array}{l}\text { Clinical trial which compared } \\
\text { Iosartan to captopril }\end{array}$ & $\begin{array}{l}\mathrm{n}=2,841 \text { ( } \mathrm{HbA1c} \text { measured at } \\
\text { baseline) } \\
\text { diabetic patients who survived an } \\
\mathrm{Ml} \text { complicated by HF }\end{array}$ & $\begin{array}{l}\text { Each } 1 \% \text { increase in } A 1 c>5 \% \text { over a } 2.5 \text { yr follow-up period } \\
\text { increased } 24 \% \text { mortality }\end{array}$ & 16 \\
\hline DECODE study & $\begin{array}{l}\text { Data on fasting and } 2 \mathrm{~h} \text { glucose } \\
\text { level on a OGTT from population- } \\
\text { based studies or large studies in } \\
\text { occupational groups in Europe }\end{array}$ & $\begin{array}{c}\mathrm{n}=\begin{array}{c}29,714 \text { participants of } 22 \\
\text { cohorts }\end{array} \\
\text { Follow up of } 11 \text { years }\end{array}$ & $\begin{array}{c}\text { Increase in postprandial glucose below the threshold for } \\
\text { diabetes diagnosis could independently predict an increased } \\
\text { risk of CV mortality }\end{array}$ & 17 \\
\hline Funagata study & Cohort population & Follow up of 7 years & IGT was a risk factor for CVD disease, but IFG was not & 18 \\
\hline ARIC study & Case-control study & $\begin{array}{l}\mathrm{n}=208 \text { normoglycemic individuals } \\
\text { with carotid initial-medial } \\
\text { thickening (case subjects) and } 208 \\
\text { normoglycemic control }\end{array}$ & $\begin{array}{l}\text { A1c and carotid intimal-medial thickening were related in } \\
\text { nondiabetic subjects }\end{array}$ & 19 \\
\hline MESA & Population-based sample & $\begin{array}{l}\text { 6,814 men and women from } 4 \\
\text { ethnic groups } \\
\text { (white, Hispanic, African American, } \\
\text { and Chinese) } \\
\text { aged } 45-84 \text { without clinical CVD } \\
\text { before recruitment }\end{array}$ & $\begin{array}{l}\text { Small differences in LVMI, volumes, and function were } \\
\text { detected among IFG and diabetes compared with those with } \\
\text { NGT; the pattern of abnormality and the degree to which risk } \\
\text { factors and subclinical atherosclerosis modified the } \\
\text { association differed by ethnicity }\end{array}$ & 20 \\
\hline Held and cols. & $\begin{array}{c}2 \text { parallel randomized controlled } \\
\text { trials } \\
\text { (ONTARGET/ } \\
\text { TRANSCEND studies) }\end{array}$ & $\begin{array}{l}\text { ONTARGET; } n=25620 \\
\text { TRANSCEND; } n=5,926 \text { ) } \\
\text { people at high risk of CVD with } \\
\text { and without a history of DM } \\
\text { 2.4-year follow-up }\end{array}$ & $\begin{array}{c}\text { FPG was modest but significant independent risk factor for } \\
\text { incident CHF hospitalization and the combined end point of } \\
\text { CHF/CV death, that persisted after adjustment for diabetes status } \\
\text { The absence of a significant interaction between patients with } \\
\text { and without known diabetes suggests that the degree of } \\
\text { dysglycemia, and not the diagnosis of DM per se, is the key of } \\
\text { that relationship }\end{array}$ & 21 \\
\hline Ingelsson and cols. & $\begin{array}{c}\text { Prospective } \\
\text { population-based cohort }\end{array}$ & $n=1,187$ Swedish men $\geq 70$ years & $\begin{array}{l}\text { Abnormal 2-h postload glucose response was an independent } \\
\text { predictor of CHF }\end{array}$ & 22 \\
\hline Nielson and Lange & $\begin{array}{l}\text { Data were extracted from the } \\
\text { Veterans Affairs electronic } \\
\text { medical record systems }\end{array}$ & $\begin{array}{l}\mathrm{n}=20,810 \text { nondiabetic patients, } \\
\text { predominantly male }\end{array}$ & $\begin{array}{l}\text { Increasing glucose in the absence of diabetes is } \\
\text { independently associated with greater incidence of } \mathrm{HF}\end{array}$ & 23 \\
\hline Reykjavik study & Population-based cohort & $n=19,381$ & $\begin{array}{l}\text { Strong associations between dysglycemia, prevalent CHF and } \\
\text { incident morbi-mortality during follow-up of } 21.3 \text { years, even } \\
\text { after adjustments for traditional risk factors }\end{array}$ & 24,25 \\
\hline
\end{tabular}

UKPDS: UK Prospective Diabetes Study; EPICNorfolk: European Prospective Investigation into Cancer in Norfolk study;

ARIC: The Atherosclerosis Risk in Communities study; MESA: Multi-Ethnic Study of Atherosclerosis; CHF: Congestive Heart Failure; CHD: Coronary Heart Disease; CV: cardiovascular; MI: myocardial ischemia; HF: heart failure; IGT: impaired glucose tolerance; IFG: impaired fasting glucose; Ref: reference. 


\section{ASSESSMENT OF DIASTOLIC FUNCTION BY DOPPLER ECHOCARDIOGRAPHY}

Diastole of the cardiac cycle has traditionally been divided into 4 phases: isovolumic relaxation; early rapid filling; diastasis; and atrial contraction. The isovolumic relaxation time is a continuum of the systolic cardiac cycle and is, therefore, dependent on systolic function in addition to relaxation of the LV. The early diastolic filling phase is dependent on both LV relaxation and chamber compliance. The slow diastolic filling phase, or diastasis, is dependent on heart rate and chamber compliance. The atrial contraction phase is dependent on the chamber compliance, left atrial (LA) function, and the electrical conduction system of the heart (26).

The clinical importance of the evaluation of diastolic function warrants a simplified approach to diastology, which is broadly accessible to general endocrinologists. Doppler echocardiography is ideally suited for assessment of diastolic function, being widely available, non-invasive, and less expensive than other techniques. However, a significant limitation is the requirement of expert interpretation of multiple parameters that vary with loading conditions and often provide conflicting information. The assessment of diastolic function should be based on a comprehensive echocardiographic study integrating all available two dimensional and Doppler data.

Echocardiographic evaluation of diastolic function has been traditionally performed by measurement of transmitral flow parameters from an apical four chamber view with conventional pulsed wave Doppler. The mitral inflow velocity profile is used to initially characterize LV filling dynamics. The E velocity (E) represents the early mitral inflow velocity and is influenced by the relative pressures between the LA and LV, which, in turn, are dependent on multiple variables including LA pressure, LV compliance, and the rate of $\mathrm{LV}$ relaxation. The A velocity (A) represents the atrial contractile component of mitral filling, and it is primarily influenced by LV compliance and LA contractility. The deceleration time (DT) of the E velocity is the interval from peak $\mathrm{E}$ to a point of intersection of the deceleration of flow with the baseline and it correlates with time of pressure equalization between the LA and LV. As the early LA and LV filling pressures either evolve toward or away from equivalence, so will the DT either shorten or lengthen respectively. Based upon age-adjusted interpretation of the transmitral flow profile, diastolic function is initially classified as either normal, impaired relaxation, pseudonormal, restrictive (which may be reversible or non-reversible with preload reduction), or indeterminate (if normal or pseudonormal cannot be differentiated).

Long axis shortening (contraction) and lengthening (relaxation) of myocardial segments result in longitudinal motion of the mitral annulus toward or away from the (relatively fixed) LV apex during systole and diastole, respectively. Although long axis segmental shortening remains fairly uniform along the myocardial wall, a gradient of increasing velocity from apex to base has been demonstrated. Mitral annular velocities may therefore be regarded as an "aggregate" of segmental myocardial velocities and in the absence of regional LV dysfunction accurately reflect global long axis LV function. The tissue Doppler imaging evaluates the early (E') and late (A') diastolic velocities that correspond to the transmitral Doppler flow. In normal subjects the E' occurs coincidently with, or just before, the transmitral E wave, whereas in HF there is a progressive delay in E' with respect to $\mathrm{E}$. The E' velocity progressively decreases as the long axis relaxation rate becomes increasingly reduced in the setting of a wide range of cardiac disease processes including dilated, restrictive, and hypertrophic cardiomyopathies. Specifically, the E' velocity is much less susceptible to the effects of increased preload and remains low in patients with advanced diastolic dysfunction and pseudonormalisation of the transmitral E velocity. Furthermore, E' is typically lower in patients with severe LV dysfunction and restrictive filling.

The colour Doppler M mode can be used to provide a two dimensional representation of the velocity of early diastolic filling as the bolus of blood propagates through the mitral valve towards the LV apex. This flow propagation velocity $(\mathrm{Vp})$ can be measured from an apical four chamber view with the $M$ mode beam aligned parallel to $\mathrm{LV}$ inflow. The $\mathrm{E} / \mathrm{Vp}$ ratio has been demonstrated to correlate with LV filling pressure (27).

\section{DYSGLYCEMIA, HYPERGLYCEMIA AND HEART FAILURE}

\section{Epidemiological clinical trials data}

The periods of impaired glucose tolerance (IGT) and undiagnosed T2DM that typically precede diagnosis of T2DM may expose individuals to more than a decade of mild to moderate hyperglycemia. Indeed, at least $25 \%$ of patients exhibit complications at the time of diagno- 
sis which could reflect, at least in part, prior exposure to hyperglycemia. Moreover, several large epidemiological studies have repeatedly shown that the degree of glucose and HbAlc elevation in diabetic patients correlates with a greater risk for CV events. For example, in an epidemiological analysis of the United Kingdom Prospective Diabetes Study (UKPDS), for each 1\% rise in $\mathrm{HbAlc}$ a $14 \%$ rise was shown in the risk for myocardial infarction, a $12 \%$ rise in the risk for stroke, and a $16 \%$ rise in the risk for congestive heart failure (CHF) (13). In the epidemiologic European Prospective Investigation into Cancer in Norfolk study, a 6-year follow-up of over 10,000 subjects ( 45 to 79 years) showed a $21 \%$ increase in $\mathrm{CV}$ events for each $1 \%$ rise in HbAlc above $5 \%$ and an increase in mortality of $24 \%$ in men and $28 \%$ in women. For every $1 \%$ of $\mathrm{HbAlc}$ above $7 \%$, the risk of a CHD event and mortality increased by $40 \%$ and $26 \%$ respectively. It is noteworthy that this relationship was independent of other CV risk factors, including age, body mass index, abdominal obesity, systolic blood pressure, cholesterol, smoking, and previous CVD (14). Meigs and cols. (15) at the Framingham Offspring Study also reported a similar independent relationship between markers of dysglycemia, including HbAlc, and incident $\mathrm{CV}$ events in a study controlled for the factors included in the Framingham Risk Score (sex, age, total and high-density lipoprotein cholesterol levels, systolic and diastolic blood pressure, DM, and smoking) (18). In a Danish study of diabetic patients who had survived myocardial ischemia complicated by HF, each $1 \%$ increase in HbAlc above 5\% over a 2.5-year follow-up period resulted in a $24 \%$ increase in mortality (16).

The DECODE study gave further insights into the topic, and reported that increased postprandial glucose excursions below the threshold for the diagnosis of DM could independently predict increased risk of CV mortality among over 25,000 subjects followed for 11 years (17). The Funagata study group interestingly showed higher CV mortality in people with IGT when compared with individuals with impaired fasting glucose (IFG) (18), suggesting the CV importance of an IGT diagnosis rather than an IFG. Furthermore, Vitelli and cols. (19) reported in The Atherosclerosis Risk in Communities Study that HbAlc and carotid intimalmedial thickening were related in nondiabetic subjects, showing a relationship of glucose levels to subclinical atherosclerosis (19).

Large epidemiological studies, including the Framingham Heart Study, the National Health and Nutri- tion Examination Survey, and the Cardiovascular Health Study, have shown that T2DM is an independent risk factor for the development of HF (28-30). In diabetic individuals, the risk of developing HF is greater in those with an elevated body mass index, poor glucose control as indicated by $\mathrm{HbAlc}$ level, nephropathy, retinopathy, and CHD (31).

However, it is not clear yet if an increased plasma glucose level below the diabetic cutoff is a risk factor for HF. Bertoni and cols. (20) investigated whether ventricular abnormalities related to DM were also observed in IFG and whether these abnormalities may be mediated by atherosclerosis in the Multi-Ethnic Study of Atherosclerosis (MESA). It was composed by a population-based sample of 6,814 men and women from four ethnic groups (white, African American, Hispanic, and Chinese) aged 45-84 without clinical CVD before recruitment. This study showed that ethnicity-specific differences in LV mass, end diastolic volume and stroke volume are associated with abnormal glucose metabolism and they are independent of subclinical CVD (20).

Held and cols. (21) identified in a large, prospective, 2.4-year follow-up of a cohort of people at high risk of CVD with and without a history of DM that fasting plasma glucose (FPG) was a modest but significant independent risk factor for incident $\mathrm{CHF}$ hospitalization and the combined end point of $\mathrm{CHF} / \mathrm{CV}$ death. These associations persisted after adjustment for diabetes status, and the absence of a significant interaction between patients with and without known DM suggests that the degree of hyperglycemia and not the diagnosis of DM per se, it was the key determinant of the relationship (21). These findings for CHF were consistent with Ingelsson and cols. (22) data in a population-based prospective study of 1,187 Swedish men older than 70 years in which an abnormal response to the 2-hour glucose value on the standard oral glucose tolerance test (as well as fasting serum proinsulin concentration and clamp glucose disposal rate) was an independent predictor for incident HF hospitalization (22).

In an investigation of 20,810 nondiabetic patients, predominantly male, receiving care in Veterans Affairs medical centers, Nielson and cols. (23) found that higher morning glucose levels were independently associated with a linear increase in the risk of incident HF as defined by clinic diagnosis or in-hospital admission. The relationship appeared to be relatively continuous without a clear lower threshold. These studies suggest that glucose intolerance may be an additional indication 
for careful clinical evaluation with respect to risks for subsequent HF (23).

The Reykjavik study of a population-based cohort ( $\mathrm{n}=19,381)$ showed strong associations between dysglycemia, prevalent CHF and incident morbidity and mortality during follow-up of an average of 21.3 years, even after adjustments for traditional risk factors, including ischemic heart disease (24). The relationship between increasing glucose levels and new onset HF was almost linear, suggesting a likely association of glucometabolic alterations and myocardial dysfunction (25).

Epidemiological studies have suggested that poor overall glucose control may be associated with an increased risk of HF among patients with DM: HbAlc higher or equal to 10 , relative to lower than 7 , implied a 1.56-fold greater risk to HF (32). At least two different epidemiological studies using sensitive diagnostic methods found the prevalence of asymptomatic diastolic dysfunction in patients with T2DM to be between $52 \%$ and $60 \%$, despite an acceptable blood glucose control $(33,34)$. Left ventricular diastolic dysfunction, characterized by impaired early diastolic filling, prolonged isovolumetric relaxation, and an increased atrial filling has been demonstrated even in young type 1 diabetic patients (35).

Similarly, our group evaluated diastolic function with pulsed tissue Doppler imaging in gestational diabetes mellitus (GDM), which is considered a harbinger of T2DM, and compared it to healthy pregnant women. During the third trimester of pregnancy and after 8 weeks postpartum the GDM group showed a different diastolic function profile. These findings suggested a mild degree of diastolic abnormality that persisted postpartum and corroborates an early $\mathrm{CV}$ involvement hypothesis in this group of women (36).

Fang and cols. (37) described in an observational study utilizing tissue Doppler imaging parameters a relationship between peak systolic strain and $\mathrm{HbAlc}$ but not for E', while Di Bonito and cols. (38) did not find any link to metabolic variables apart from an association of E'/A' with insulin resistance. Bajraktari and cols. (39) recently demonstrated that insulin resistance (IR) was associated with impaired diastolic function of the LV in subjects with either IGT or T2DM (39).

In a cohort of hospitalized nondiabetic patients with HF, elevated admission blood glucose levels were independently associated with significant in-hospital and 60-day mortality increase. These findings may have clinical implications as a potential new marker for early risk stratification and detection of a high-risk subset of patients admitted because of $\mathrm{HF}(40)$.

\section{Experimental animal data}

The natural history of DM heart function by Doppler echocardiography is limited, because most patients do not have a prediabetic study, and most patients receive treatments in the full-blown stage of DM or after having diabetes complications. Therefore, the use of an appropriate animal model may allow a better understanding of the processes that lead to diabetic cardiac dysfunction.

The Otsuka Long-Evans Tokushima Fatty (OLETF) rat was recently established as an animal model of congenital DM by selective mating. The strain manifests stable clinical and pathological features that resemble human T2DM. Briefly, the characteristics of this strain are late onset of hyperglycemia, a mild and chronic course of DM, mild obesity, inheritance by males, and renal and cardiac complications. Using this model, the serial changes in LV filling dynamics histopathology and metabolic disorders, such as hyperglycemia, myocardial collagen accumulation, hyperinsulinemia, and IR during the process of DM progression have been evaluated.

OLETF rat hyperglycemia was associated with an increased deposition of collagen in the myocardium and a reduced peak velocity and prolonged deceleration time of early transmitral flow during the pre-stage of T2DM (41). In addition, rodent models of chronic DM also demonstrate abnormalities in diastolic LV function, with or without systolic LV dysfunction $(12,42,43)$.

Evidence of cardiomyopathy has also been demonstrated in animal models of both type 1 (streptozotocininduced diabetes) and T2DM (Zucker diabetic fatty rats and $o b / o b$ or $d b / d b$ mice). During IR or T2DM, the heart rapidly modifies its energy metabolism, shifting metabolism towards increased fatty acid (FA) utilization and decreased glucose consumption (44).

\section{Perspectives on glucose level interventions}

Preliminary clinical observations suggest that early myocardial and microcirculatory dysfunction induced by elevated glucose levels are dynamic and may be reversed by improved metabolic control $(45,46)$. In a pilot study, von Bibra and cols. $(46,47)$ indicated that optimized glucose control, especially if insulin-based, may improve LV diastolic function and myocardial 
blood flow reserve during stress. In this observational study, patients with T2DM referred to a diabetic clinic due to poor metabolic control were monitored for diastolic dysfunction and impaired coronary flow reserve. Following three weeks of improved insulin-based glucose control, there was an improvement in diastolic function and capillary perfusion. In a more recent study the authors extended the observation time to up to 52 weeks, and they showed that diastolic function may be also favorably influenced by an improved glucose control in the long term $(46,47)$.

Jarnert and cols. (48), from the Karolinska Institute in Stockholm, engaged in a larger randomized trial (DM and diastolic dysfunction; DADD) which evaluated the impact of strict glycemic control upon myocardial diastolic function and perfusion in patients with T2DM. Nevertheless, the DADD trial failed to confirm the results of the previous observational study (48).

The effect of a 1 year physical training was investigated by Loimaala and cols. (49) in a controlled trial where tissue Doppler imaging recognized a slightly compromised diastolic function in 48 male patients with T2DM without other signs of CVD. Although this study showed that training improved glycemic control, no clear impact on diastolic function could be observed (49).

In intensive care, the hyperglycemic (diabetic and nondiabetic) individual who has sustained an MI has an increased risk of HF and death (50). Euglycemia, obtained with intravenous insulin therapy, has been shown to greatly improve the prognosis for both the diabetic and the nondiabetic patient with stress hyperglycemia (51).

\section{PATHOPHYSIOLOGY}

The heart is one of the most metabolically active organs in the body. Under normal physiological conditions it can utilize multiple substrates including fatty acids (FA), carbohydrate, amino acids, and ketones. Among these substrates, carbohydrates and FA are the major sources of energy. In a normal heart, $70 \%$ of adenosine triphosphate (ATP) generation is through FA oxidation owing to the high energy yield per molecule of substrate metabolized, whereas glucose and lactate account for approximately $30 \%$ of the energy provided to the cardiac muscle. Meanwhile, it should be noted that the heart can rapidly switch its substrate selection to glucose, a more efficient fuel, to accommodate different physiological and pathophysiological conditions involving altered extracellular hormones, substrate availabili- ty and energy demand, as in stress states (e.g., ischemia, pressure load, injury) (44).

Several potential explanations exist for the observed relationship between FPG and CHF. First, people with glucose intolerance exhibit higher LV mass and wall thickness than people who are normoglycemic (52), possibly explained by the formation of advanced glycosylation end-products in the myocardium, leading to myocardial stiffness (53). Second, the previously described relationship between dysglycemia and CVD risk suggests that individuals with higher FPG levels have more underlying coronary artery disease. Hyperglycemia may have unfavorable effects on the heart by inducing inflammation, modulating nitric oxide metabolism, and increasing oxidative stress (54), which are all factors involved in the development of atherosclerosis and further damage and dysfunction of the myocardium. Third, high FPG levels have been shown to induce activation of signaling involving endothelial apoptosis (55). Fourth, hyperglycemic individuals are generally hyperinsulinemic, and the high insulin levels may promote increased ventricular mass and decreased cardiac output (56). Fifth, hyperglycemic individuals are also insulin resistant, which is an independent predictor of incident CHF after accounting for DM or obesity (20). Finally, activation of the sympathetic nervous system either by the high insulin levels (57) or possibly secondary to glucose-induced diuresis may promote CHF.

Ren and Davidoff (58) demonstrated that shortterm hyperglycemia modifies cardiomyocite contraction and relaxation in an experimental model of isolated ventricular myocites (58). In addition, a study of Fang and cols. (37) performed on diabetic patients showed that hyperglycemia and insulin resistance are able to induce functional and structural changes of cardiomyocites, which lead to progressive deterioration of regional and global myocardial dynamics (37).

A recent study used LV endomyocardial biopsies and assessed the relative contributions of AGE deposition, fibrosis, cardiomyocyte hypertrophy, and cardiomyocyte resting tension to the high diastolic LV stiffness of the failing diabetic heart (59). In diabetic patients with diastolic HF, cardiomyocyte hypertrophy and high cardiomyocyte resting tension were mainly responsible for the increase in diastolic LV stiffness, whereas in diabetic patients with systolic HF, AGE deposition and fibrosis were the main contributors to diastolic LV dysfunction. 
The possible molecular mechanisms of diastolic dysfunction associated with impaired glucose tolerance can be divided into factors intrinsic to the myocardium, factors affecting the cardiac myocytes and the extracellular matrix, and factors affecting the vascular system. In diabetics, chronic hyperglycemia leads to non-enzymatic glycation of vascular and membrane proteins, producing either advanced glycation end-products or reactive oxygen species. Once such end-products develop in the myocardium and arterial wall, they form stable and irreversible cross-links with collagen polymers, thereby decreasing the compliance of the myocardium and vessels. Thus, cardiac stiffness increases and leads to diastolic dysfunction (60). Diabetes is also characterized by an increase of free fatty acid turnover (42), which increases myocardial oxygen consumption and enhances the intracellular accumulation of intermediates, leading to various deleterious effects. In animals with IGT, collagen-linked glycation has been reported to affect cardiac stiffness leading to diastolic dysfunction. Impaired glucose oxidation also results in lactic acid accumulation that further promotes the degradation of free fatty acids. In summary, the mechanisms by which diastolic dysfunction may occur in patients with IGT appear to be similar to those operating in DM (60).

The frequent association of DM with hypertension, retinopathy, nephropathy, and CVD has implicated the rennin angiotensin system (RAS) in the initiation and progression of these disorders. This has been demonstrated by clinical trials in which RAS inhibitors significantly reduced the incidence of vascular complications in DM patients (61). RAS components, mostly Ang II, have a potential role in endothelial cell dysfunction, IR, inflammation, and proliferative effects. Angiotensin (Ang) II exerts physiological and biochemical actions that could contribute to these complications. It was originally thought that Ang II mediated all actions of the RAS. Over the past few years, other angiotensin peptides, like Ang III, Ang IV, and especially Ang-(1-7) were shown to selectively mediate different RAS effects (61).

One of the most relevant conceptual changes in our understanding of the RAS was the discovery of local or tissue RAS. A local system is characterized by the presence of RAS components, such as angiotensinogen, processing enzymes, angiotensins, and specific receptors at tissue level. The local RAS has been found in the heart, blood vessels, kidney, adrenal gland, pancreas, central nervous system, reproductive system, lymphatic and adipose tissue. Other important landmarks for the new concept of RAS were the characterization of Ang(1-7) as a biological active metabolite of RAS.

Ang-(1-7) has been associated to the physiopathology of several diseases such as hypertension, preeclampsia, hypertrophic myocardial disease and CHF, MI, chronic renal diseases, diabetic nephropathy, GDM and cirrhosis $(62,63)$. Further studies should try to better elucidate the role of Ang-(1-7), as opposed to Ang II, in diabetes.

\section{CONCLUSION}

The term "dysglycemia" has been advocated to describe the state of having a level of plasma glucose above that at which adverse outcomes are likely to occur (64). In the aforementioned studies a growing body of evidence on the association between dysglycemia and HF was highlighted, but these studies still raise many questions. Indeed, they do not describe the potential role of intercurrent events such as acute coronary syndromes or even changes in blood pressure accounting for subsequent hospitalization for HF. Dysglycemia is often described as associated with a diffuse and aggressive form of coronary artery disease, which could potentially lead to myocardial injury and failure.

Another confounding issue is the known high prevalence of dysglycemia in patients with asymptomatic LV systolic dysfunction. This topic raises the question of whether dysglycemia serves as a marker for a preexisting potentially unrecognized ventricular dysfunction. Conversely, DM and dysglycemia are described as associated with worse symptoms and lesser functional capacity in patients with HF and LV systolic dysfunction, which raises the possibility of early HF recognition in these dysglycemic patients. However, other factors commonly associated to dysglycemia should also be controlled in order to better address this issue, including renal dysfunction and the concomitant therapies such as the use of thiazide diuretics.

On the other hand, dysglycemia may, in some way, be directly implicated in the pathophysiology of a developing HF. However, glucose per se might not be the culprit, and hyperinsulinemia could be very important, by causing myocardial hypertrophy. Several other mechanisms have been suggested, including: the formation of AGE products causing collagen cross-linking and reducing ventricular distensibility and vascular compliance; AGE products causing modification of sarcoplasmic/ endoplasmic reticulum $\mathrm{Ca}^{2+}$ ATPase; hyperglycemia and 
its association to oxidative stress; altered intracellular signaling; decreased vascular endothelial growth factor production; and some altered gene expression. Furthermore, autonomic neuropathy and microangiography are well recognized complications of DM which may also develop in the early stages of dysglycemia, and myocardial metabolism may become more dependent on free FA in dysglycemic states resulting in uncoupling of oxidative phosphorylation potentially reducing contractility.

The observation that increased glucose indicates risk for $\mathrm{HF}$ is of potential clinical importance regardless of whether glucose is an independent risk or a covariant to other recognized risk factors. However, there is little clinical evidence that improved glucose control can improve cardiac function and prevent HF. Further studies should address this topic in the near future. A better understanding of this issue will help clarify the role of therapeutic intervention to dysglycemia, and the clinical approach of dysglycemic states may finally be recognized as an important tool for stopping the epidemic prevalence of HF by acting on its early disease stages.

Disclosure: no potential conflict of interest relevant to this article was reported.

\section{REFERENCES}

1. Hunt SA, Abraham WT, Chin MH, Feldman AM, Francis GS, Ganiats TG, et al. ACC/AHA 2005 guideline update for the diagnosis and management of chronic heart failure in the adult: a report of the American College of Cardiology/American Heart Association Task Force on Practice Guidelines (Writing Committee to Update the 2001 Guidelines for the Evaluation and Management of Heart Failure).

2. Zarich SW, Arbuckle BE, Cohen LR, Roberts M, Nesto RW. Diastolic abnormalities in young asymptomatic diabetic patients assessed by pulsed Doppler echocardiography. J Am Coll Cardiol. 1988;12:114-20.

3. Diabetes Control and Complications Trial Research Group: the effect of intensive treatment of diabetes on the development and progression of long-term complications in insulin-dependent diabetes mellitus. N Engl J Med. 1993;329:977-86.

4. UK Prospective Diabetes Study Group: intensive blood-glucose control with sulphonylureas or insulin compared with conventional treatment and risk of complications in patients with type 2 diabetes (UKPDS 33). Lancet. 1998;352:837-53.

5. Bianchi C, Miccoli R, Penno G, Del Prato S. Primary prevention of cardiovascular disease in people with dysglycemia. Diabetes Care. 2008;31:S208-14.

6. Ray KK, Seshasai SR, Wijesuriya S, Sivakumaran R, Nethercott $S$, Preiss $D$, et al. Effect of intensive control of glucose on cardiovascular outcomes and death in patients with diabetes mellitus: a meta-analysis of randomized controlled trials. Lancet. 2009;373:1765-72.

7. Henry RMA, Paulus WJ, Kamp O, Kostense PJ, Spijkerman AMW, Dekker JM, et al. Deteriorating glucose tolerance status is associated with left ventricular dysfunction - the Hoorn Study. Neth J Med. 2008;66:110-7.
8. Gerstein HA. Disturbed glucose metabolism state (dysglicaemia) is a key risk factor for cardiovascular events. Eur Heart J Supplements. 2003;5:B1-2.

9. Rubler S, Dlugash J, YuceogluYZ, KumralT, Branwood AW, Grishman A. New type of cardiomyopathy associated with diabetic glomerulosclerosis. Am J Cardiol. 1972;30:595-602.

10. Nichols GA, Gullion CM, Koro CE, Ephross SA, Brown JB. The incidence of congestive heart failure in type 2 diabetes: an update. Diabetes Care. 2004;27:1879-84.

11. Berg TJ, Snorgaard O, Faber J, Torjesen PA, Hildebrandt P, Mehlsen J, et al. Serum levels of advanced glycation end-products are associated with left ventricular diastolic function in patients with type 1 diabetes. Diabetes Care. 1999;22:1186.

12. Fang $Z Y$, Prins JB, Marwick TH. Diabetic cardiomyopathy: evidence, mechanisms, and therapeutic implications. Endocr Rev. 2004;25(4):543-67.

13. Stratton IM, Adler Al, Neil HA, Matthews DR, Manley SE, Cull CA, et al. Association of glycaemia with macrovascular and microvascular complications of type 2 diabetes (UKPDS 35): prospective observational study. BMJ. 2000;321:405-12.

14. Khaw KT, Wareham N, Bingham S, Luben R, Welch A, Day N. Association of hemoglobin A1c with cardiovascular disease and mortality in adults: the European prospective investigation into cancer in Norfolk. Ann Intern Med. 2004;141:413-20.

15. Meigs JB, Nathan DM, D'Agostino RB Sr, Wilson PW. Fasting and postchallenge glycemia and cardiovascular disease risk: the Framingham Offspring Study. Diabetes Care. 2002;25:1845-50.

16. Gustafsson I, Kistorp CN, James MK, Faber JO, Dickstein K, Hildebrandt PR. OPTIMAAL Study Group. Unrecognized glycometabolic disturbance as measured by hemoglobin A1c is associated with a poor outcome after acute myocardial infarction. Am Heart J. 2007;154:470-6.

17. The DECODE Study Group on behalf of the European Diabetes Epidemiology Group. Is the current definition for diabetes relevant to mortality risk from all causes and cardiovascular and noncardiovascular diseases? Diabetes Care. 2003;26:688-96.

18. Tominaga M, Eguchi $H$, Manaka $H$, Igarashi $K$, Kato T, Sekikawa A. Impaired glucose tolerance is a risk factor for cardiovascular disease, but not impaired fasting glucose:The Funagata Diabetes Study. Diabetes Care. 1999;22:920-4.

19. Vitelli LL, Shahar E, Heiss G, McGovern PG, Brancati FL, Eckfeldt $\mathrm{JH}$, et al. Glycosylated hemoglobin level and carotid intimal medial thickening in non-diabetic individuals. The Atherosclerosis Risk in Communities Study. Diabetes Care. 1997;20: 1454-8.

20. Bertoni AG, Goff DC, D'Agostino RB, Liu K, Hundley WG, Lima JA, et al. Subclinical cardiovascular disease: The Multi-Ethnic Study of Atherosclerosis (MESA). Diabetes Care. 2006;29:588-94.

21. Held C, Gerstein HC, Yusuf $S$, Zhao F, Hilbrich L, Anderson $C$, et al.; for the ONTARGET/TRANSCEND Investigators. Glucose levels predict hospitalization for congestive heart failure in patients at high cardiovascular risk. Circulation. 2007;115:1371-5.

22. Ingelsson E, Sundstrom J, Arnlov J, Zethelius B, Lind L. Insulin resistance and risk of congestive heart failure. JAMA. 2005;294:334-41.

23. Nielson C, LangeT. Blood glucose and heart failure in nondiabetic patients. Diabetes Care. 2005;28:607-11.

24. Thrainsdottir IS, Aspelund T, Thorgeirsson G, Gudnason V, Hardarson $\mathrm{T}$, Malmberg $\mathrm{K}$, et al. The association between glucose abnormalities and heart failure in the populationbased Reykjavik study. Diabetes Care. 2005;28:612-6.

25. Thrainsdottir IS, Aspelund T, Gudnason V, Malmberg K, Sigurdsson G, Thorgeirsson G, et al. Increasing glucose levels and BMI predict future heart failure experience from the Reykjavik Study. Eur J Heart Fail. 2007;9:1051-7.

26. Khouri SJ, Maly GT, Suh DD, Walsh TE. A practical approach to the echocardiographic evaluation of diastolic function. J Am Soc Echocardiogr. 2004;17:290-7. 
27. Mottram PM, MarwickTH. Assessment of diastolic function: what the general cardiologist needs to know. Heart. 2005;91:681-95.

28. Kannel WB, Hjortland M, Castelli WP. Role of diabetes in congestive heart failure: the Framingham study. Am J Cardiol. 1974;34:29-34.

29. He J, Ogden LG, Bazzano LA, Vupputuri S, Loria C, Whelton PK, et al. Risk factors for congestive heart failure in US men and women: NHANES I epidemiologic follow-up study. Arch Intern Med. 2001;161:996-1002.

30. Gottdiener JS, Arnold AM, Aurigemma GP, Polak JF, Tracy RP, Kitzman DW, et al. Predictors of congestive heart failure in the elderly: the Cardiovascular Health Study. J Am Coll Cardiol. 2000;35:1628-37.

31. Petrie MC, McMurray JJV. Dysglycemia and heart failure hospitalization: What is the link? Circulation. 2007;115:1334-5.

32. Iribarren C, Karter AJ, Go AS, Ferrara A, Liu JY, Sidney S, et al. Glycemic control and heart failure among adult patients with diabetes. Circulation. 2001;103:2668-73.

33. Poirier P, Bogaty P, Garneau C, Marois L, Dumesnil JG. Diastolic dysfunction in normotensive men with well-controlled type 2 diabetes: importance of maneuvers in echocardiographic screening for preclinical diabetic cardiomyopathy. Diabetes Care. 2001;24:5-10.

34. Redfield MM, Jacobsen SJ, Burnett JC, Mahoney DW, Bailey KR, Rodeheffer RJ. Burden of systolic and diastolic ventricular dysfunction in the community. JAMA. 2003;289:194-202.

35. Schannwell CM, Schneppenheim M, Perings S, Plehn G, Strauer $\mathrm{BE}$. Left ventricular diastolic dysfunction as an early manifestation of diabetic cardiomyopathy. Cardiology. 2002;98:33-9.

36. Freire CMV, Nunes MC, Barbosa MM, Longo JR, Nogueira Al, Diniz SS, et al. Gestational diabetes: a condition of early left ventricular diastolic abnormalities. J Am Soc Echocardiogr. 2006;19:1251-6.

37. Fang ZY, Schull-Meade R, Downey M, Prins J, Marwick TH. Determinants of subclinical diabetic heart disease. Diabetologia. 2005;48:394-402.

38. Di Bonito P, Moio N, Cavuto L, Covino G, Murena E, Scilla C, et al. Early detection of diabetic cardiomyopathy: usefulness of tissue Doppler imaging. Diabet Med. 2005;22:1720-5.

39. Bajraktari G, Koltai MS, Ademaj F, Rexhepaj N, Qirko S, Ndrepepa $\mathrm{G}$, et al. Relationship between insulin resistance and left ventricular diastolic dysfunction in patients with impaired glucose tolerance and type 2 diabetes. Int J Cardiol. 2006;110: 206-11.

40. Barsheshet A, Garty M, Grossman E, Sandach A, Lewis BS, Gottlieb $S$, et al. Admission blood glucose level and mortality among hospitalized nondiabetic patients with heart failure. Arch Intern Med. 2006;166:1613-9.

41. Mizushige K, Yao L, Noma T, Kiyomoto H, Yu Y, Hosomi N, et al. Alteration in left ventricular diastolic filling and accumulation of myocardial collagen at insulin resistant prediabetic stage of a type II diabetic animal model. Circulation. 2000;101:899-1009.

42. Rodrigues B, Cam MC, McNeill JH. Metabolic disturbances in diabetic cardiomyopathy. Mol Cell Biochem. 1998;180:53-7.

43. Severson DL. Diabetic cardiomyopathy: recent evidence from mouse models of type 1, and type 2 diabetes. Can J Physiol Pharmacol. 2004;82:813-23.

44. Ding An, Rodrigues B. Role of changes in cardiac metabolism in development of diabetic cardiomyopathy Am J Physiol Heart Circ Physiol. 2006;291:1489-506.

45. Rask-Madsen C, Ihlemann N, Krarup T, Christiansen E, Kober L, Nervil Kistorp C, et al. Insulin therapy improves insulin-stimulated endothelial function in patients with type 2 diabetes and ischemic heart disease. Diabetes. 2001;50:2611-8.

46. von Bibra H, Hansen A, Dounis V, Bystedt T, Malmberg K, Ryden L. Augmented metabolic control improves myocardial diastolic function and perfusion in patients with non-insulin dependent diabetes. Heart. 2004;90:1483-4.

47. von Bibra H, SiegmundT, Hansen A, Jensen J, Schumm-Draeger PM. Augmentation of myocardial function by improved glycemic control in patients with type 2 diabetes mellitus. Dtsch Med Wochenschr. 2007;132:729-34.

48. Jarnert C, Landstedt-Hallin L, Malmberg K, Melcher A, Ohrvik J, Persson $\mathrm{H}$, et al. A randomized trial of the impact of strict glycaemic control on myocardial diastolic function and perfusion reserve: a report from the DADD (Diabetes mellitus And Diastolic Dysfunction) study. Eur J Heart Fail. 2009;11:39-47.

49. Loimaala A, Groundstroem K, Rinne M, Nenonen A, Huhtala H, Vuori I. Exercise training does not improve myocardial diastolic tissue velocities in Type 2 diabetes. Cardiovasc Ultrasound. 2007;5:32

50. Wahab NN, Cowden EA, Pearce NJ, Gardner MJ, Merry H, Cox JL. Is blood glucose an independent predictor of mortality in acute myocardial infarction in the thrombolytic era? J Am Coll Cardiol. 2002;40:1748-54.

51. Malmberg K, Ryden L, Efendic S, Herlitz J, Nicol P, Waldenstrom $A$, et al. Randomized trial of insulin-glucose infusion followed by subcutaneous insulin treatment in diabetic patients with acute myocardial infarction (DIGAMI study): effects on mortality at 1 year. J Am Coll Cardiol. 1995;26:57-65.

52. Rutter MK, Parise H, Benjamin EJ, Levy D, Larson MG, Meigs JB, et al. Impact of glucose intolerance and insulin resistance on cardiac structure and function: sex-related differences in the Framingham Heart Study. Circulation. 2003;107:448-54.

53. Jyothirmayi GN, Soni BJ, Masurekar M, Lyons M, ReganTJ. Effects of metformin on collagen glycation and diastolic dysfunction in diabetic myocardium. J Cardiovasc Pharmacol. 1998;3:319-26.

54. Devos P, Chiolero R, Van den Berghe G, Preiser JC. Glucose, insulin and myocardial ischemia. Curr Opin Clin Nutr Metab Care. 2006;9:131-9.

55. Yokoi T, Fukuo K, Yasuda O, Hotta M, Miyazaki J, Takemura Y, et al. Apoptosis signal-regulating kinase 1 mediates cellular senescence induced by high glucose in endothelial cells. Diabetes. 2006;55:1660-5.

56. Holmang A, Yoshida N, Jennische E, Waldenstrom A, Bjorntorp $P$. The effects of hyperinsulinaemia on myocardial mass, blood pressure regulation and central hemodynamics in rats. Eur J Clin Invest. 1996;26:973-8.

57. Anderson EA, Hoffman RP, Balon TW, Sinkey CA, Mark AL. Hyperinsulinemia produces both sympathetic neural activation and vasodilation in normal humans. J Clin Invest. 1991;87:2246-52.

58. Ren J, Davidoff AJ. Diabetes rapidly induces contractile dysfunctions in isolated ventricular myocites. Am J Physiol. 1997;272:H148-58.

59. Van Heerebeek L, Paulus WJ. Invasive evaluation of diastolic left ventricular dysfunction. In: Smiseth O, Tendera M, eds. Diastolic heart failure. London: Springer; 2007. p. 137-48.

60. Fujita M, Asanuma H, Kim J, Liao Y, Hirata A, Tsukamoto O, et al. Impaired glucose tolerance: a possible contributor to left ventricular hypertrophy and diastolic dysfunction. Int $\mathrm{J}$ Cardiol. 2007;118(1):76-80.

61. Ribeiro-Oliveira A Jr, Nogueira Al, Pereira RM, Boas WW, Dos Santos RA, Simoes e Silva AC. The renin-angiotensin system and diabetes: an update. Vasc Health Risk Manag. 2008;4(4):787-803.

62. Nogueira Al, Souza Santos RA, Simoes e Silva AC, Cabral AC, Vieira RL, Drumond TC, et al. The pregnancy-induced increase of plasma angiotensin-(1-7) is blunted in gestational diabetes. Regul Pept. 2007;141(1-3):55-60.

63. Vilas-Boas WW, Ribeiro-Oliveira A Jr, Pereira RM, Ribeiro RC, Almeida J, Nadu AP, et al. Relationship between angiotensin-(1-7) and angiotensin correlates with hemodynamic changes in human liver cirrhosis. World J Gastroenterol. 2009;15(20):2512-9.

64. Gerstein HC, Yusuf S. Dysglycaemia and risk of cardiovascular disease. Lancet. 1996;347:949-50. 